Research Article

\title{
Research on Optimal Investment Reinsurance of Insurance Companies under Delayed Risk Model
}

\author{
Yun Xiao ${ }^{1,2}$ and Zhijian Qiu ${ }^{1}$ \\ ${ }^{1}$ School of Economic Mathematics, Southwestern University of Finance and Economics, Chengdu, Sichuan 610000, China \\ ${ }^{2}$ School of Mathematics, Yibin University, Yibin, Sichuan 644007, China \\ Correspondence should be addressed to Yun Xiao; xy@yibinu.edu.cn
}

Received 8 November 2021; Revised 6 December 2021; Accepted 7 December 2021; Published 27 December 2021

Academic Editor: Gengxin Sun

Copyright (c) 2021 Yun Xiao and Zhijian Qiu. This is an open access article distributed under the Creative Commons Attribution License, which permits unrestricted use, distribution, and reproduction in any medium, provided the original work is properly cited.

\begin{abstract}
The reinsurance and investment portfolio of insurance companies has always been a hot issue in insurance business. In insurance practice, it is inevitable for insurance companies to invest their own funds in order to expand their capital scale and enhance market competitiveness so as to obtain greater returns. At the same time, in order for insurance companies to disperse insurance risks and to avoid too concentrated claims or catastrophes caused by failure to perform compensation responsibilities, the purchase of reinsurance business has also become an important way. Stochastic control theory is widely used in reinsurance and investment issues. Based on the reinsurance system architecture, this paper establishes a reinsurance delay risk investment model, which reduces the amount of claims to be borne by buying proportional reinsurance to avoid bankruptcy caused by the excessive amount of claims. By using the delayed venture capital model to describe the earnings of insurance companies, the optimal investment and reinsurance strategy are solved under the optimization criterion of minimizing the probability of bankruptcy. By analyzing the model parameter data, the influence of each parameter on optimal investment strategy and optimal reinsurance strategy is discussed.
\end{abstract}

\section{Introduction}

With the continuous improvement of people's living standards, the insurance industry has also developed vigorously. The types of insurance products are also derived from the initial marine insurance, fire insurance, life insurance, liability insurance, and other kinds of insurance. Insurance institutions have developed from cooperative organizations organized by people to commercial institutions and insurance companies. The risks insured have evolved from simple maritime transport risks to catastrophic risks such as fire and earthquake and other risks. Modern insurance industry has become an indispensable part of people's daily life. The insurer undertakes certain compensation liability according to the extent of possible accidents agreed in the contract [1]. Insurance is a means of pooling insurance costs. The premium is mainly used to compensate the loss caused by the insured. Insurance is also a method of risk management to disperse risks. Through insurance, people can gather together and convert individual risks into common risks, thus improving people's ability to bear losses caused by risks. The main function of insurance is to disperse risks and share losses. Reinsurance is based on the mathematical calculation, the probability theory of reasonable risk allocation to minimize losses.

As people accumulate more wealth, relative risk becomes more concentrated and has a wider reach. The organization that underwriter establishes to serve specially for policyholder is called insurance company. After the insurance company collects the premium from the insurer, it invests the premium in the financial market and pays the confirmed insurance claim to the insurer through the income from the investment [2]. In this process, on the one hand, insurance companies want to share part of the risk through risk transfer; on the other hand, they want to ensure that their investment strategies can increase the premium income. 
Therefore, risk transfer and optimal return are the main tasks of insurance companies. Although from privately owned insurance premium, insurance liability insurance law, reinsurance, and other parties in the face of the insurance company risk management code, the complexity analysis and the quantitative model, the lack of personnel of experience with sex, and cross functional division of responsibilities coordinate the difficulty of communication, greatly increase the risk of insurance company management difficulty, and threaten the survival and development of the insurance company. For an insurance company to gain a firm foothold in the market, it must first be able to bear the risk claim. However, sometimes the claim risk is too large and exceeds the business scope of the insurance company, so it involves the risk control of the insurance company at this time. The insurance company will consider transferring the excess claim risk to other insurance companies, which is also known as reinsurance. The core task of insurance company is to ensure normal operation, so the investment portfolio of insurance company asset management is also the means of premium appreciation. Insurance companies will collect the premium capital investment in bonds, stocks, loans, and other assets, using the income from these assets to pay the insurance claims determined by the policy. Through business, insurance companies can obtain high returns on investment and provide customers with appropriate insurance services at lower premiums, so as to make profits.

The development of the industrial revolution results in a large number of industrial accidents and intensified labour contradictions. In order to ease the conflict between the bourgeoisie and the working class, the bourgeoisie made some laws to protect the interests of workers [3]. According to the public safety law, the bourgeoisie needs to bear the legal liability for damage to the life and property of workers, so liability insurance also developed. Insurance companies face two kinds of risks in the process of operation, namely, compensation risk and investment risk. Risk to the insurance company operating soundness and financial arrangements bring a huge impact, even leading to the bankruptcy of insurance companies. But for the insurance market, the channels for risk diversification are not that rich. The reinsurance surcharge rate is higher than the original insurance surcharge rate. When too much reinsurance is purchased, the income of the insurance company will be negative. In order to make profits, insurance companies usually retain part of the risk to obtain excess returns and increase insurance income. So, the determination of retention is particularly important for insurance companies, especially those engaged in catastrophe insurance business. If the retention amount is too much, the insurance company undertakes too much risk. When the risk breaks out at one time, the cash flow of the insurance company is likely to be interrupted. With too little retention, insurance companies have to pay too high reinsurance premiums, which reduces profitability and may even lead to negative profitability. The detailed introduction of reinsurance strategy enables insurance companies to ensure excess returns, fully disperse catastrophe risks, and enhance business initiative. Insurance companies will consider transferring the risk of claims that exceed their capacity to other insurance companies [4]. The premiums collected by insurance companies are simply not enough to cover the amount they pay out. In order to better manage, insurance companies invest part of the premiums they receive in risk and part in risk-free investment. How to arrange the investment portfolio to reduce the investment risk and obtain stable and rich investment return is another problem that insurance companies need to pay attention to. In the management of insurance companies, in order to reduce their own risks and avoid bankruptcy cases where huge accidents cannot be fulfilled due to the concentration of claim risk, insurance companies bear part of the risks and liabilities and reinsurance to other insurers. The business operation of insurance companies has a certain degree of stability Therefore, the choice of investment strategy will affect the income of insurance company to a great extent. Insurance companies effectively control risk investment and reinsurance strategies to maximize the utility of the company's expected wealth or minimize the probability of bankruptcy which has become an important research topic.

In this paper, the reinsurance system establishes the reinsurance delay risk investment model and obtains the optimal investment and reinsurance strategy. The influence of each parameter on optimal investment strategy and optimal reinsurance strategy is discussed.

\section{Related Work}

With the vigorous development of financial market and insurance market, risk theory has become an important part of financial investment and insurance mathematics. In the past decades, risk control theory has developed rapidly with the help of the concepts and methods of stochastic control and stochastic analysis. Insurance companies are faced with two main risks, one is the underwriting risk brought by the claim process, and the other is the investment risk in the financial market. In order to better deal with these two kinds of risks, insurance companies always regard investment reinsurance as the core content of concern. This is also a hot topic of actuarial and mathematical research. The commonly used utility functions are exponential utility function, logarithmic utility function, and power utility function. Under the utility maximization rule, Chen and Shen assume that the surplus process of insurance company meets jump-spread risk model, and the correlation between underwriting risk and investment risk is got byb the insurance companies related to the optimal investment strategy [3]. Lin et al. allowed insurance companies to invest on multiple risky assets, in this model, to study the optimal investment reinsurance of insurance company. In the case that the risk-free interest rate is zero, the strategy under the expected utility maximization criterion of the terminal wealth index is equivalent to the strategy under the bankruptcy probability minimization criterion [5]. Cummins and Weisset al. promoted the claim process of insurance companies from a composite Poisson process to a pure jump process. Under this model, the optimal result under exponential utility was obtained [6]. Kunreuther used martingale method to solve the problem of optimal 
investment of insurance companies in the market. The author considers that insurance companies can diversify underwriting risks by purchasing proportional reinsurance and obtains insurance companies' investment reinsurance strategies under exponential utility and power utility [7]. PateCornell et al. studied the optimal investment reinsurance strategy when insurance companies purchase excess loss reinsurance, assuming that the surplus process of insurance companies obeys the jump-diffusion model, and obtained the optimal investment and proportional reinsurance strategy. In the case that risk assets obey the stochastic volatility model, the maximum principle is used to work out the investment reinsurance strategy under the mean-variance criterion [8].

With the rapid development of economy, the competition of insurance companies is increasingly fierce. Insurance companies attract policy-holders by lowering premiums in order to occupy a place in the market as soon as possible. As a result, insurance companies charge lower and lower premiums, which lead to losses or even bankruptcy if they spend more than they earn. Insurance companies also buy a certain percentage of reinsurance to reduce their own risk. So, choosing the optimal investment and reinsurance strategy is of great significance to the operation and development of insurance companies. Franke found that when the risk aversion coefficient is constant, the investment amount in risk assets has nothing to do with the current wealth [9]. Vermeulen et al. added state-dependent risk aversion coefficient into the meanvariance criterion. Under this model, a time-consistent balanced investment strategy was obtained [10]. Felicio and Rodrigues et al. assumed that the claim process of insurance companies was partially observable and adopted filtering technology to transform the problem under partial information into an equivalent problem under complete information. Under the expected utility maximization criterion [11], Layton et al. assume that the drift term of risk assets is partially observable, use Markov modulation mechanism transformation model to describe the expected return rate of risk assets, and study the balanced investment reinsurance strategy of insurance companies under the mean-variance criterion [12]. Although the study of the theory of risk has obtained many important results and conclusions, the actual market is too complex, not enough thoughtful scholars when doing the research, such as the lack of considering the risk-free asset, only single risky asset price process being studied, and the optimal control strategy with the claims process model, and so on. Therefore, when we study the optimal investment and reinsurance strategy of insurance companies, we should focus on the actual situation of the financial market to establish the model and use stochastic control and stochastic analysis methods to get the corresponding optimal control strategy.

\section{Optimal Investment Reinsurance of Insurance Companies under the Delayed Risk Model}

3.1. Reinsurance. Insurance companies, as financial institutions operating in debt, face various complex risks. These risks have an important impact on the assets and values of insurance companies and then affect the operation and management of insurance companies. The main risks include claim risk, asset price fluctuation risk, policy risk, interest rate risk, credit risk, liquidity risk, operational risk, and so on. The basis of reinsurance is primary insurance, and the emergence of reinsurance is precisely based on the need of risk diversification in the operation of primary insurer [13]. Therefore, insurance and reinsurance complement each other in that they spread the risk of assets. Reinsurance is a further continuation of insurance and an integral part of insurance business. The relationship between reinsurance and primary insurance is shown in Figure 1. Both coinsurance and reinsurance have the effect of dispersing risks, expanding underwriting capacity, and stabilizing operating results. The main body of former insurance concern is the underwriter and policy-holder or insurant, which reflect the economic relation between the underwriter and insurant. The main body that reinsurance concerns is former underwriter and reinsurance person, which reflect the economic concern of underwriter. The subject matter insured by the original insurance includes property, person, liability, credit, and related interests. The insurance mark of reinsurance is the risk responsibility that former underwriter place assumes; it is a kind of insurance that has liability insurance property. Original insurance includes compensatory sex contract and pay sex contract of two kinds; reinsurance contract is compensatory sex contract.

3.2. Reinsurance System Framework. Reinsurance, as the "insurance of insurance," is an important means for insurance companies to disperse business risks, balance financial status, and expand underwriting capacity [14]. In order to meet the established business and technical requirements, the reinsurance business processing system adopts the current mature architecture, using WebLogic as the application server and Tuxedo as the middleware. The business logic is encapsulated in Java beans or EJBs, and the interaction with other systems is encapsulated as Tuxedo service, which facilitates the portability of the database. In the actual design and implementation of the reinsurance business processing system, the system is based on the MVC programming design idea of Struts, which separates the user display interface, process control, and business logic. On the client side, the user submits the requirements, and the data information is submitted to the Web server as request or FormBean. In the Web server, Struts Action performs the major work of data encapsulation and process forwarding. The Action Servlet acts as a controller, and the control logic is configured using the Struts-config.xml file. At the model layer, THE EJB handles the business logic, the algorithms involved in customizing the model are all done in the EJB, and the database is accessed to access the data. In the design and implementation, the whole system structure is divided into four layers, and the system architecture is shown in Figure 2.

The JSP layer is responsible for displaying the interface and interacting with the user. The data input by the user is submitted for background processing and the result data is displayed. 


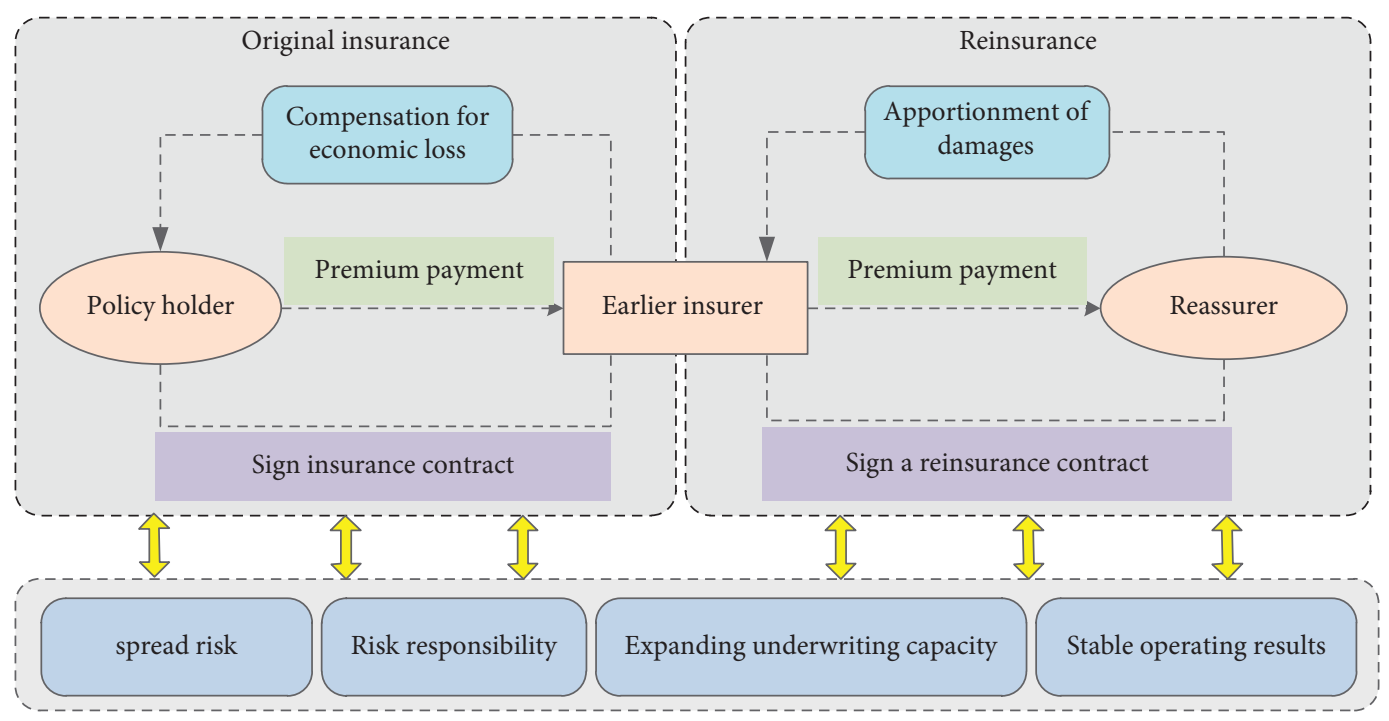

FIGURE 1: Reinsurance and primary insurance relationship diagram.

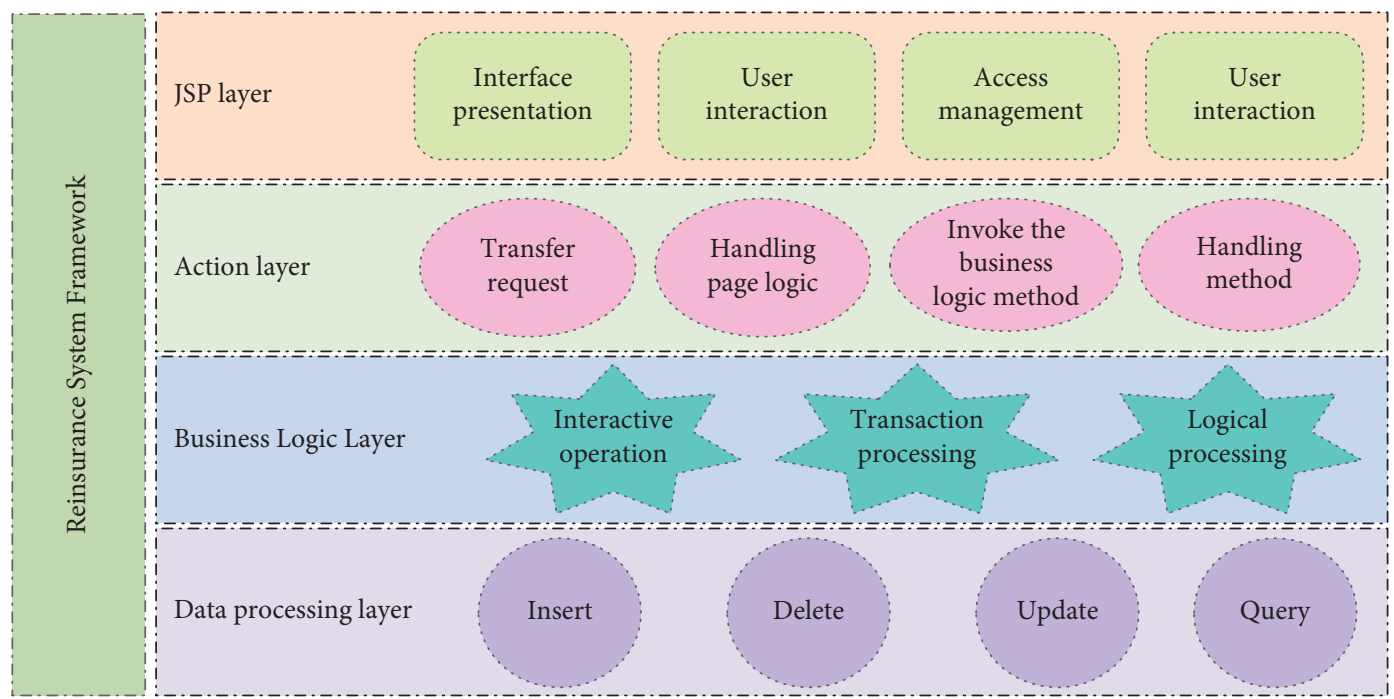

FIgURE 2: Reinsurance system architecture diagram.

Action layer is responsible for the distribution of JSP layer transfer request, processing page logic, call business logic method, submitted to the business layer in the relevant class, and method for further processing. Business layer according to the business logic processing and according to the request of Action layer transaction completes the logical processing of the external interface between subsystems. In these processes, the operations that involve interacting with the database are left to the lowest level. The data processing layer is responsible for the interaction with the database, mainly for the database table insertion, deletion, update, and query operations.

3.3. Reinsurance Delay Risk Investment Model. In the classic risk model [15], the earnings process of the insurer can be described as

$$
M(t)=u+\mathrm{mt}+Z(t)=u+\mathrm{mt}+\sum_{i=1}^{t} Y_{i}
$$

where $u$ is the initial capital of the insurance company and $m$ is the premium rate. The claim number process $\{N(t): t \geq 0\}$ is a Poisson process with a density parameter $\lambda$. The claim amount $\left\{Y_{i}: I \geq 1\right\}$ is a series of positive random variables independent of each other and the same distribution and independent of $\{N(t)\}$. For simplicity, let us say $Y$ is a general random variable and has the same distribution function as $Y_{i}$. The first and second moments of $Y$ are denoted as $\mu_{1}=\mathrm{EY}$ and $\mu_{2}=E\left[Y^{2}\right]$, and the moment generating function is denoted as $M_{Y}(\rho)=E\left(e^{\rho Y}\right)$. Suppose there exists some constant $0<\zeta \leq+\infty$ and for $0<\rho<\zeta$. According to Grandell [16], the claim process can be approached by diffusion with Brownian motion with drift, that is, diffusion claim model. 


$$
Z(t)=\mathrm{ht}+\sigma w(t)
$$

where $W(t)$ is a standard Brownian motion, $h=\lambda \mu_{1}$, and $\sigma=\lambda \mu_{2}$. Thus, the surplus process can be expressed as

$$
M(t)=u+m t+\lambda \mu_{1} t+\lambda \mu_{2} w(t) .
$$

It is assumed that the insurance company purchases proportional reinsurance to transfer some risks and writes the retention ratio function as an adaptation process $q(t) \epsilon$ $[0,1]$. If the retention ratio at time $t$ is $Q(t)$, the premium paid to the reinsurance company is $\delta(q(t))$, and the reinsurance premium charged by the reinsurance company is calculated according to the variance principle, and the reinsurance premium is obtained.

$$
\delta(q(t))=(1+q(t)) h+o(1+q(t))^{2} \sigma^{2},
$$

where $(\lambda>0)$ is the safety loading factor of the reinsurance company; let

$$
\eta=\frac{(m-h)}{\sigma^{2}} .
$$

The safety load factor of insurance company satisfies the basic condition $\lambda>\eta \geq 0$. Then consider the net profit bar.

$$
m+\delta(q(t))+q(t) h \geq 0 .
$$

Solution is

$$
q(t) \geq 1+\sqrt{\frac{\eta}{o}}
$$

Let $q=q(t), q$ is a threshold, and this threshold plays a very important role in discussing proportional reinsurance. The surplus process then becomes

$$
\mathrm{d} M^{q}(t)=[m+\delta(q(t))] \mathrm{d} t+\mathrm{hq}(t) \mathrm{d} t+\sigma q(t) \mathrm{d} W(t) .
$$

\subsection{Insurance Company Optimal Investment Reinsurance} Strategy. Insurance companies can not only use reinsurance to disperse risks, so as to improve their ability to deal with risks, but also use investment strategies to disperse risks and improve returns. The resource allocation of insurance companies in various markets can directly affect the company's earnings and risks $[17,18]$. In the operation of reinsurance business, two or more parties to a reinsurance contract enable an insurance company to take less risk or make more profit, optimize the company's investment portfolio, and ensure that the company has sufficient solvency. Every insurance company wants to minimize risk or possible compensation and maximize profits. Among the fixed income products issued by insurance, asset management, and securities companies, a small amount of equity investment can be appropriately allocated to some of the underlying products to increase the income of the products.

In the process of underwriting risk, diffusion approximation is used to better study the optimal decision problem. This paper considers the choice of earnings investment strategy under the minimum probability of bankruptcy [19]. Insurance companies generally invest their surplus in both the risk and risk-free markets. Assuming that the insurer invests part of the surplus in the stock market, its price process happens to obey the geometric Brownian motion. A is the expected return rate of stock instantaneous conditional, $b$ is the standard deviation of stock instantaneous conditional, and $W_{t}$ is the standard Brownian motion and is independent of $B_{t}$.

The other part is invested in the bond market, whose price process satisfies the differential equation $\mathrm{d}_{t}=r Q_{t} \mathrm{~d} t$, where $r$ is the risk-free interest rate.

Remember that the insurer invests part of the surplus in the risk market at time $T$, and the total surplus after selection is denoted as the surplus of risk-free investment. Then the earnings process after embedding investment strategy on the basis of original earnings satisfies the following stochastic differential equation:

$$
\mathrm{d} t=\left[\beta u+(\alpha-r) \pi_{t}+A\right] \mathrm{d} t+b \pi_{t} \mathrm{~d} W_{t}-\mathrm{BdBt},
$$

where $W_{t}$ and $B_{t}$ are independent of each other.

Now the goal is to find the optimal strategy among all feasible strategies to minimize the probability of bankruptcy, denoted as $\psi(u)$.

In order to solve the optimization problem, the stochastic Markov control theory and the HJB equation are adopted. If the second-order of the optimal value function is continuously differentiable, the $\psi(u)$ must satisfy the following HJB equation:

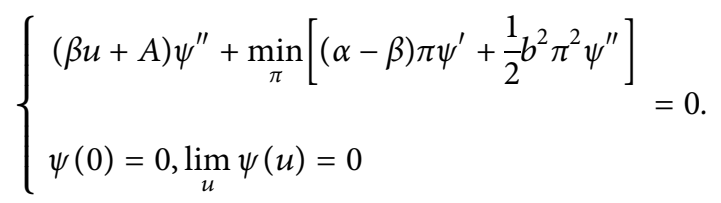

The quadratic continuous differentiable solution of the HJB equation is sought as follows. According to [20], the optimal amount of venture capital is the corresponding value of the square quotient of the drift term and the fluctuation term in the maximized surplus process. We just have to solve for theta.

$$
\phi(\pi)=\frac{\beta u+(\alpha-r) \pi}{b^{2} \pi^{2}+B^{2}} .
$$

If $\varphi(\pi)=0$, the following formula can be obtained:

$$
\begin{gathered}
\pi(u)=\frac{1}{\alpha-r}\left[(\beta u+A)+\sqrt{(\beta u+A)^{2}+\left(B \frac{\alpha-\beta}{b}\right)^{2}}\right] \\
A=-\lambda \mu_{x}-\lambda \mu_{y}, B=\sqrt{\lambda\left(\mu_{x}+\mu_{y}+2 \mu_{x} \mu_{x}\right)} .
\end{gathered}
$$

To solve the optimal value function, assume that the function is convex [21]. Therefore, the optimal solution should satisfy HJB equations (10) and (1) and be the unique solution; the following equation can be obtained: 


$$
\pi(u)=\frac{\alpha-\beta}{b^{2}} \times \frac{\psi^{\prime \prime}(u)}{\psi^{\prime}(u)}
$$
(14).

The solution is obtained by combining formulae (12) and

$$
\psi^{\prime}(u)=\psi^{\prime}(0) \exp \left(\frac{\alpha-\beta}{b^{2}} \int_{0}^{u} \frac{1}{\pi(u)} \mathrm{d} u\right),
$$

where $\pi(u)$ is determined by formula (12) and can be further obtained.

$\psi(u)=\int_{0}^{u} \psi^{\prime}(u) \mathrm{d} u=\psi^{\prime}(0) \int_{0}^{u} \exp \left(\frac{\alpha-\beta}{b^{2}} \int_{0}^{u} \frac{1}{\pi(\theta)} d \theta\right) \mathrm{d} u$, where $\psi^{\prime}(0)$ can be obtained from the following boundary condition formula:

$$
\lim _{u \longrightarrow \infty} \psi(u)=0 .
$$

Under the diffusion approximation form of delayed risk model, the minimum bankruptcy probability of optimization problem with investment is

$$
\psi(u)=\frac{\int_{0}^{u} \exp [\pi(u)] \mathrm{d} u}{\int_{0}^{\infty} \exp [\pi(u)] \mathrm{d} u} .
$$

The optimal investment strategy is

$$
\pi(u)=\frac{1}{\alpha-r}\left[\left(\beta u-\lambda \mu_{x}-\lambda \mu_{y}\right)+\sqrt{(\beta u+A)^{2}+\left(\sqrt{\lambda\left(\mu_{x}+\mu_{y}+2 \mu_{x} \mu_{y}\right) \times \frac{\alpha-\beta}{b}}\right)^{2}}\right] .
$$

Under the optimal criterion of minimizing bankruptcy probability, the explicit expressions of optimal investment strategy and minimum bankruptcy probability are determined by the parameters of claim amount and venture capital.

Under the optimization criterion of minimizing the probability of bankruptcy, the claim amount to be borne is reduced by buying proportional reinsurance to avoid bankruptcy caused by excessive claim amount. Reinsurance companies mix proportional reinsurance and invest in the financial market with inflation risk. Through the principle of dynamic programming, the optimal reinsurance and investment strategy and the expression of maximization of expected utility of terminal wealth are obtained. The risk model of reinsurance companies accords with the reality.

\section{Numerical Analysis}

4.1. Influence of Model Parameters on Investment Strategy. When the risk assets reach the expected rate of return, the investment amount changes with the expected rate of return, and the insurer can obtain higher investment income on the risk assets [22]. Therefore, at this time, the insurer will invest more in the risky assets to obtain higher investment returns. The insurer's investment amount in risk assets is lower than the insurer's investment amount in risk assets. The insurer only has information about the price process of risk assets and can only estimate the expected return rate of risk assets. In this case, the insurer is relatively conservative and more cautious in investment in risk assets.

Figure 3 shows the effect of parameter $\beta$ on the optimal investment strategy. It can be seen from the figure that when $\rho=1$, the optimal investment strategy is a subtraction function of $\beta$. When $\rho>0$, the correlation between underwriting risk and investment risk is positive. When $\beta$ increases, the insured risk will increase with the increase of $\beta$. Therefore, in order to reduce the total risk, the insurer will reduce the amount of investment in risky assets. When $\rho=-1$, the optimal strategy is an increasing function of $\beta$. In the case of $\rho<0$, the correlation between underwriting risk and investment risk is negative. When beta increases, the insurer can get higher returns from risky assets. Therefore, the insurer wants to invest a higher amount in risky assets to obtain a higher return.

As the expected return of risk assets increases, insurance companies will get more benefits from investing in risk assets. Therefore, insurance companies are more willing to invest insurance funds in risk assets. On the contrary, when the risk-free interest rate increases, the proportion of investment in risk-free assets will decrease, because the higher the risk-free interest rate is, the higher the income of insurance companies investing in risk-free assets will be. Because the risk-free asset is not affected by nonsystematic risks, when the risk-free rate of return is high, insurance companies can get stable and rich returns on investment in the risk-free asset. In this case, insurance companies are certainly willing to invest more funds in the risk-free asset.

4.2. Influence of Model Parameters on Reinsurance Strategy. Figure 4 shows sensitivity analysis of optimal reinsurance strategy under risk model.

Figure 4 shows the impact of safety load $\theta$ on reinsurance strategy. According to the figure, $\theta$ has a positive effect on reinsurance strategy. As theta increases, reinsurance costs become more expensive and insurers want to increase retention, the minus function of theta. When reinsurance premiums become expensive, reinsurers want to share more reinsurance to get higher premium returns. The figure shows the influence of risk factor on reinsurance strategy. The insurer's risk factor $\gamma 1$ has a negative effect on reinsurance 


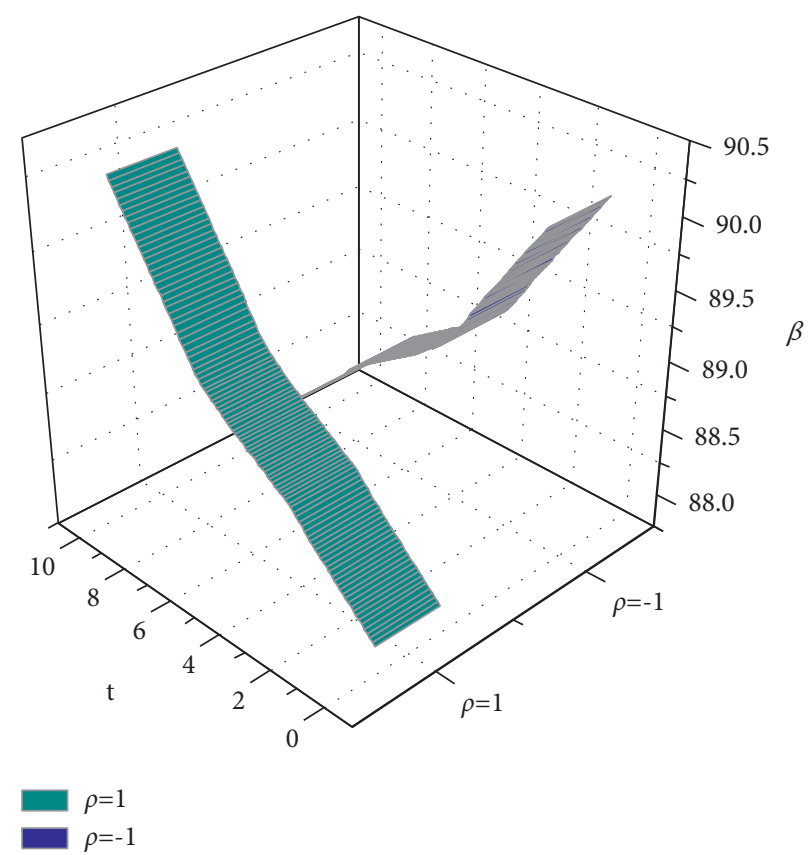

Figure 3: The influence of parameter $\beta$ on the function.

strategy. Therefore, when the risk aversion coefficient $\gamma 1$ of the insurer increases, the insurer will buy more reinsurance to hedge the risk. The reinsurance strategy of the reinsurer is the increment function of $\gamma 2$. When $\gamma 2$ increases, reinsurers will be more conservative. Therefore, reinsurers will assume a lower proportion of reinsurance to control risks.

When the insurance company for catastrophe insurance business arrangement is small in the initial surplus, especially early operation in the operation, its ruin probability is very big and it will face a higher risk of insolvency; to resist the risk, the insurance company will generally choose more risky asset allocation, with more insurance funds to invest in risky assets, in order to gain a higher return on investment. That, though, would mean greater risk for an insurance company or for an insurance business. In fact, small insurance companies often allocate more funds in equity investment and option investment. When catastrophe insurance business has a high initial surplus, insurance companies will choose to invest more insurance funds in risk-free assets for safety purposes to achieve stability.

\subsection{Influence of Model Parameters on Equilibrium Reinsur-} ance Strategy. Figure 5 shows the influence of model parameters on the equilibrium excess loss reinsurance strategy.

According to Figure 5, the equilibrium excess loss reinsurance strategy is a subtractive function of $\alpha$. When $\alpha$ increases, the interests of the insurer are more valued in the decision-making process. From the perspective of the insurer, in order to disperse underwriting risks, the insurer will choose to reduce the retention ratio and buy more reinsurance. In addition, equilibrium excess loss reinsurance increases with the increase of the safety load $\eta$ of reinsurers. When $\eta$ increases, the cost of reinsurance will be higher, and the insurer will choose to increase the retention ratio to reduce the reinsurance cost. Equilibrium excess loss reinsurance strategy with respect to the insurer's risk aversion coefficient $\gamma$ increases and decreases. With the increase of the risk aversion coefficient of the insurer, the insurer will be more conservative. Therefore, the insurer will buy more reinsurance to transfer the underwriting risk to the reinsurance company. The risk aversion coefficient of reinsurance strategy decreases with the increase of $\gamma$. The larger $\gamma$ is, the more risk averse the reinsurer is, so the reinsurer will reduce the reinsurance business to reduce the total risk.

\subsection{Influence of Model Parameters on Equilibrium Investment} Strategy. According to Figure 6, the equilibrium investment strategy is the increasing function of the competition coefficient of insurance companies. When $K$ increases, the insurance company will pay more attention to the impact of competition on the company. At this time, in order to obtain higher investment returns, it will increase the investment in risk assets, so as to enhance its competitiveness. Figure 6 shows that the equilibrium investment strategy is an increasing function of time $t$. At the initial moment, the amount of investment in risk assets of insurance companies is relatively low. As time goes by, insurance companies will become more stable and have the ability to increase their investment in risk assets. It increases with the increase of the correlation coefficient of risk assets. When $\rho$ is large, insurance companies pay more attention to competition, so they will invest more money in risk assets to improve their competitiveness.

Figure 7 shows that the balanced investment strategy increases as the expected return rate of risky assets increases. When $\mu$ increases, the insurance company can get higher returns on risky assets, so it will increase the amount of investment in risky assets. In addition, when $\rho>0$, it 


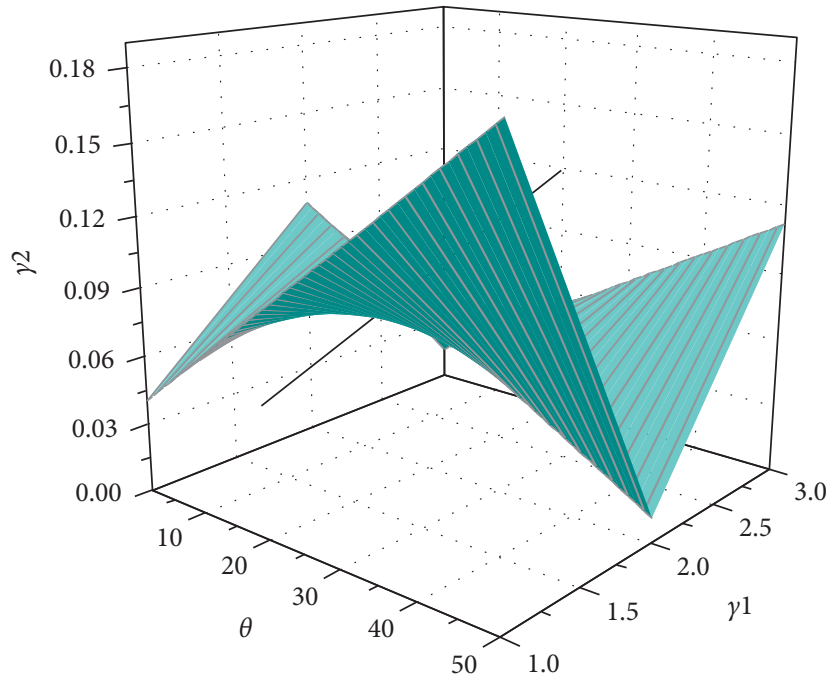

Figure 4: Effects of parameters $\theta$ and $\gamma$ on reinsurance strategy.
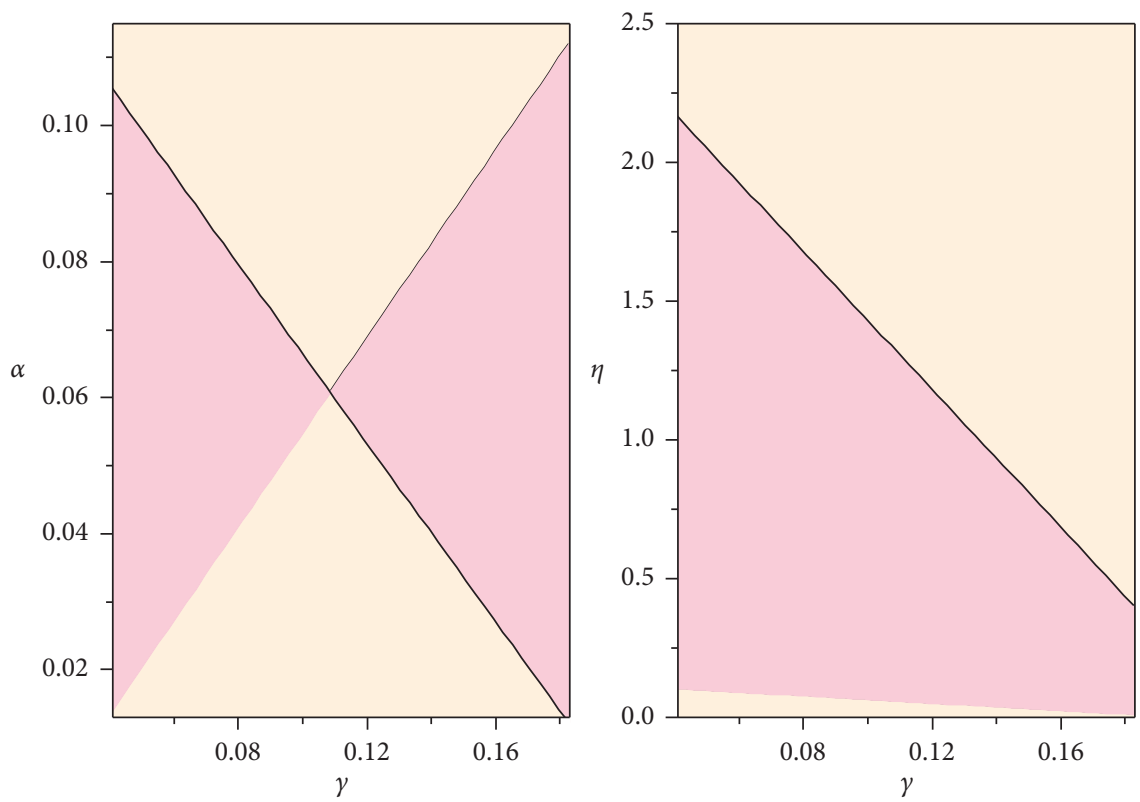

FIgURE 5: Influence of model parameters on equilibrium excess loss reinsurance strategy.

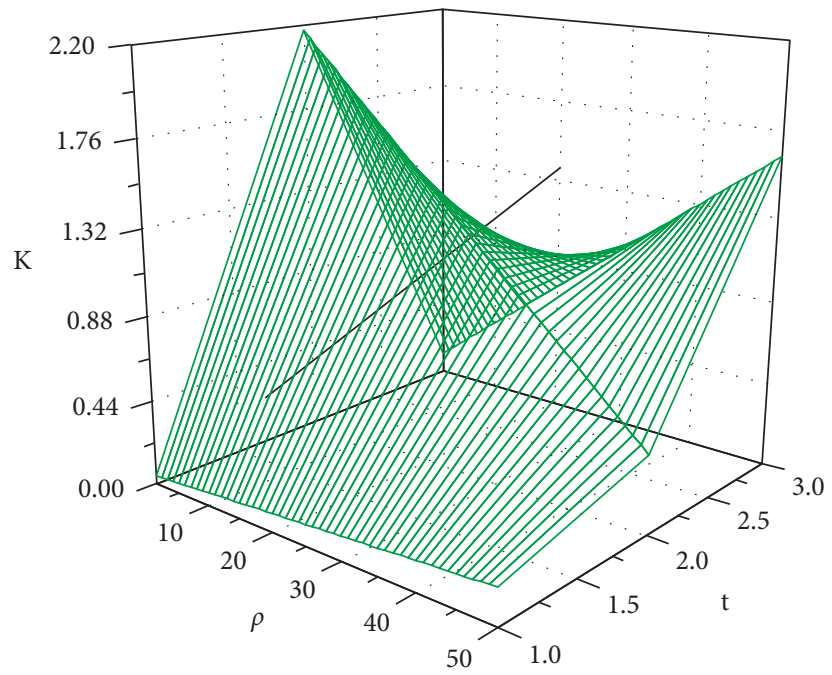

Figure 6: The influence of model parameters $K$ and $\rho$ on investment. 


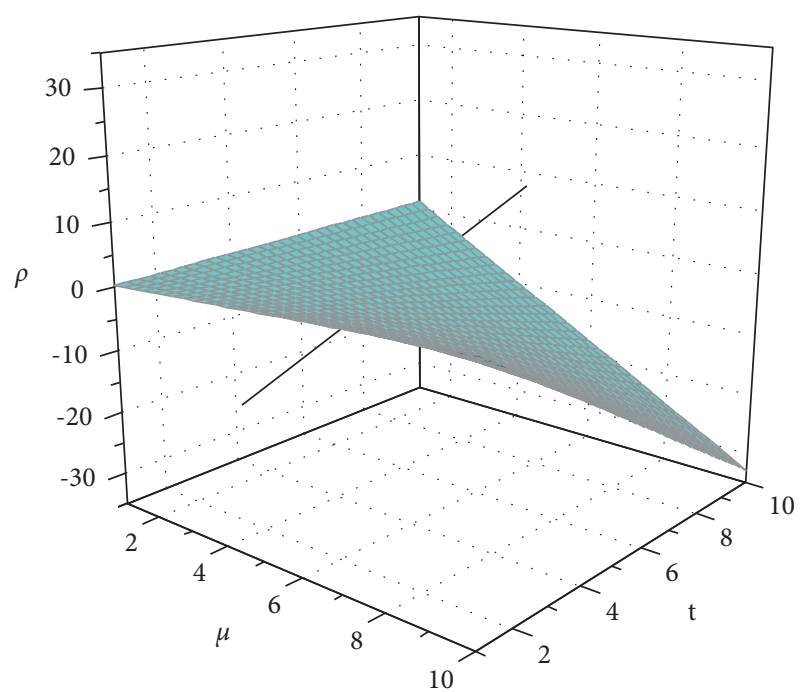

Figure 7: The influence of model parameters $\mu$ and $\rho$ on investment.

increases with the increase of $\mu$. When $\rho<0$, it decreases with the increase of $\mu$. When $\rho>0$, there is a positive correlation between risk assets, and when $\mu$ increases, the first insurance company will get higher returns on risk assets. On the contrary, in the case of $\rho<0$, when $\mu$ increases, the first insurance company may get less investment returns on risky assets, so it will reduce the amount of investment in risky assets.

\section{Conclusion}

With the rapid development of the insurance industry, insurance company has to increase the utilization rate of capital surplus capital investment to the capital market and at the same time buy reinsurance to transfer risk, based on the reinsurance system architecture reinsurance delay risk investment model which is established, by buying a proportional reinsurance to reduce bearing the claim amount and avoid bankruptcy claim amount that is too large. $\mathrm{Nu}$ merical analysis shows that when the insurer's risk coefficient $\gamma_{1}$ increases, the insurer will buy more reinsurance to hedge the risk. The reinsurance strategy of the reinsurer is the increment function of $\gamma_{2}$. When $\gamma_{2}$ increases, reinsurers will assume a lower proportion of reinsurance to control the risk. It increases with the increase of the correlation coefficient of risk assets. When $\rho$ is large, insurance companies pay more attention to competition, and they will invest more money in risk assets to improve their competitiveness. The actual value of the risk model of the real situation faced by the insurance company is greater. The optimal investment and reinsurance strategies of insurance companies are obtained under the optimization criterion of minimizing the probability of bankruptcy. The conclusion of this paper is based on the ideal complete financial market, but the real financial market is always with friction, so we can consider the establishment of a market model including transaction costs, non-short selling restrictions, and dividends. Since the insurance market and financial market have different risk attributes, the same measure transformation is usually used to deal with these two markets, which is not consistent with the actual situation. Future studies will make further studies in this aspect.

\section{Data Availability}

The data used to support the findings of this study are available from the corresponding author upon request.

\section{Conflicts of Interest}

The authors declare that they have no conflicts of interest.

\section{Acknowledgments}

This study was supported by the Scientific Research Fund of Science and Technology Department of Sichuan Provincial: "Study on Financial Problems of Enterprise Supply Chain Based on Fuzzy Game" (no. 2020134).

\section{References}

[1] Y. Shen and Y. Zeng, "Optimal investment-reinsurance with delay for mean-variance insurers: a maximum principle approach," Insurance: Mathematics and Economics, vol. 57, pp. 1-12, 2014.

[2] C. A and Z. Li, "Optimal investment and excess-of-loss reinsurance problem with delay for an insurer under Heston's SV model," Insurance: Mathematics and Economics, vol. 61, pp. 181-196, 2015.

[3] L. Chen and Y. Shen, "On a new paradigm of optimal reinsurance: a stochastic Stackelberg differential game between an insurer and a reinsurer," ASTIN Bulletin: The Journal of the IAA, vol. 48, no. 2, pp. 905-960, 2018.

[4] S. Liu, Y. Dai, Z. Cai, X. Pan, and C. Li, "Construction of double-precision wisdom teaching framework based on blockchain technology in cloud platform," IEEE Access, vol. 9, pp. 11823-11834, 2021.

[5] Y. Lin, J. Yu, and M. O. Peterson, "Reinsurance networks and their impact on reinsurance decisions: theory and empirical evidence," Journal of Risk and Insurance, vol. 82, no. 3, pp. 531-569, 2015.

[6] J. D. Cummins and M. A. Weiss, "Equity capital, internal capital markets, and optimal capital structure in the US property-casualty insurance industry," Annual Review of Financial Economics, vol. 8, no. 1, pp. 121-153, 2016.

[7] H. Kunreuther, "The role of insurance in reducing losses from extreme events: the need for public-private partnerships," The Geneva Papers on Risk and Insurance-Issues and Practice, vol. 40, no. 4, pp. 741-762, 2015.

[8] M.-E. Pate-Cornell, M. Kuypers, and M. Smith, "Cyber risk management for critical infrastructure: a risk analysis model and three case studies," Risk Analysis, vol. 38, no. 2, pp. 226-241, 2018.

[9] U. Franke, "The cyber insurance market in Sweden," Computers \& Security, vol. 68, pp. 130-144, 2017.

[10] R. Vermeulen, E. Schets, and M. Lohuis, "The heat is on: a framework for measuring financial stress under disruptive energy transition scenarios," Ecological Economics, vol. 190, Article ID 107205, 2021.

[11] J. Augusto Felício and R. Rodrigues, "Organizational factors and customers' motivation effect on insurance companies' 
performance," Journal of Business Research, vol. 68, no. 7, pp. 1622-1629, 2015.

[12] T. J. Layton, T. G. McGuire, and A. D. Sinaiko, "Risk corridors and reinsurance in health insurance marketplaces: insurance for insurers," American Journal of Health Economics, vol. 2, no. 1, pp. 66-95, 2016.

[13] T.-O. Leautier, "The visible hand: ensuring optimal investment in electric power generation," The Energy Journal, vol. 37, no. 2, pp. 89-109, 2016.

[14] H. Gründl and J. Gal, "The evolution of insurer portfolio investment strategies for long-term investing," OECD Journal: Financial Market Trends, vol. 2016, no. 2, 55 pages, 2017.

[15] R. V. Hill, N. Kumar, N. Magnan et al., "Ex ante and ex post effects of hybrid index insurance in Bangladesh," Journal of Development Economics, vol. 136, pp. 1-17, 2019.

[16] M. Bijlsma and R. Vermeulen, "Insurance companies' trading behaviour during the European sovereign debt crisis: flight home or flight to quality?" Journal of Financial Stability, vol. 27, pp. 137-154, 2016.

[17] T. Jun-Feng and G. Rui-Fang, "An efficient and revocable auditing scheme for the internet of things," Communications in Computer and Information Science, vol. 1298, pp. 109-119, 2020.

[18] V. Trynchuk, I. Khovrak, R. Dankiewicz, A. OstrowskaDankiewicz, and A. Chushak-Holoborodko, "The role of universities in disseminating the social responsibility practices of insurance companies," Problems and Perspectives in Management, vol. 17, no. 2, pp. 449-461, 2019.

[19] M. Eling and M. Lehmann, "The impact of digitalization on the insurance value chain and the insurability of risks," The Geneva Papers on Risk and Insurance-Issues and Practice, vol. 43, no. 3, pp. 359-396, 2018.

[20] B. Li, D. Li, and D. Xiong, "Alpha-robust mean-variance reinsurance-investment strategy," Journal of Economic Dynamics and Control, vol. 70, pp. 101-123, 2016.

[21] Q. Zhang and P. Chen, "Optimal reinsurance and investment strategy for an insurer in a model with delay and jumps," Methodology and Computing in Applied Probability, vol. 22, no. 2, pp. 777-801, 2020.

[22] S. Zhang, J. Xiong, and X. Zhang, "Optimal investment problem with delay under partial information," Mathematical Control \& Related Fields, vol. 10, no. 2, p. 365, 2020. 